\title{
Erratum to: Mapping FLS2 function to structure: LRRs, kinase and its working bits
}

\author{
Silke Robatzek • Lennart Wirthmueller
}

Published online: 27 November 2013

(C) Springer-Verlag Wien 2013

Erratum to: Protoplasma (2013) 250:671-681

DOI: 10.1007/s00709-012-0459-6

Unfortunately, after publication of our review article, it was brought to our attention that the amino acid sequence given for the transmembrane domain of FLS2 in Figure 3 is actually shown as that of LRR17. We have corrected this and changed Figure 3 accordingly.

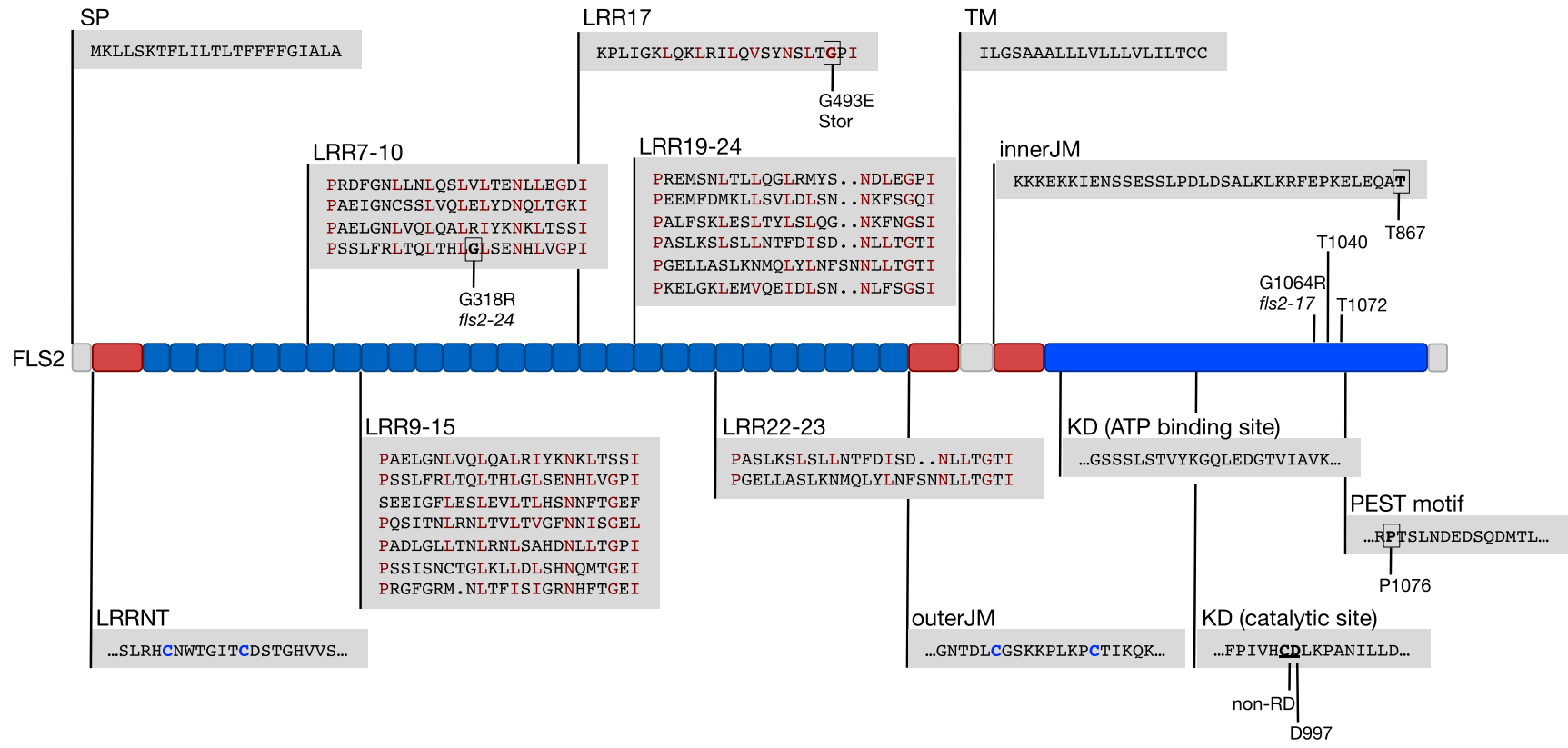

The online version of the original article can be found at http://dx.doi.org/ 10.1007/s00709-012-0459-6.

S. Robatzek $(\bowtie) \cdot$ L. Wirthmueller

The Sainsbury Laboratory,

Norwich Research Park, Norwich NR4 7UH, UK

e-mail: robatzek@tsl.ac.uk 